\title{
A FormaÇÃo Docente Continuada PaRa AS RelaÇões ÉtNiCo-RaCiaIS no Rio de Janeiro: A eXPeriênCia do Programa de Estudo Sobre o Negro NA SOCIEDAdE BRASILEIRA (PENESB/UFF)
}

\section{THE CONTINUED TEACHING TRAINING FOR ETHNIC-RACIAL RELATIONS IN RIO DE JANEIRO: THE EXPERIENCE OF THE PENESB / UFF COURSE}

\begin{abstract}
Vitor Leandro de Souza
Doutorando em História Social da Cultura pela Pontifícia Universidade Católica do Rio de Janeiro. Professor do Colégio Stella Maris. Rio de Janeiro - RJ - Brasil vitorleandro@id.uff.br
\end{abstract}

Tiago Dionísio da Silva Mestre em Educação pela Universidade Federal Rural do Rio de Janeiro. Formador da área de Ciências Humanas da Secretaria Estadual de Educação do Rio de Janeiro. Rio de Janeiro - RJ - Brasil tiago_dionisio@hotmail.com.br

Tatiane Pacheco de Mattos Mestre em Educação pela Universidade Federal Rural do Rio de Janeiro.Professora das Redes Municipal de Mesquita e Estadual do Rio de Janeiro. Rio de Janeiro - RJ - Brasil prof.tatianerj@gmail.com

Resumo: Após 15 anos da aprovação da Lei $n^{\circ}$ 10.639/2003, sobre a obrigatoriedade do ensino da História e Cultura Afro-Brasileira, percebemos inúmeros entraves para sua implantação dentre eles a formação docente. Neste texto refletimos sobre os marcos legais que tangem a formação continuada, desaguando posteriormente na Educação das Relações Étnico-Raciais e, por fim, nas experiências teórico-metodológica do curso de especialização em Educação e Relações Raciais do PENESB/UFF. Tal experiência se mostra original e diferenciada frente aos demais cursos existentes no estado do Rio de Janeiro, pois além de ter como objetivo central a intervenção e transformação da realidade a partir do chão da sala de aula, também leva em consideração os fatores que impedem aos professores da Educação Básica investirem em seus estudos.

Palavras-chave: Formação Continuada. Relações Étnico-Raciais. PENESB/UFF.

Cadernos de Pós-graduação, São Paulo, v. 17, n. 2, p. 75-97, jul./dez. 2018. 
Abstract: After 15 years of the approval of Law number 10.639 / 2003, on the compulsory teaching of Afro-Brazilian Culture and History, we realized that are a large number of obstacles to the total implementation of that program, among them, the teaching training. In this article, we reflect about the legal frameworks for continuing education, which later developed into the Education of Ethnic-Racial Relations and, finally, the theoretical-methodological experiences of the specialization course in Education and Racial Relations of PENESB / UFF. This experience is original and differentiated in comparison to other courses in the Rio de Janeiro state, because besides having as a central objective the intervention and transformation of reality of the classroom, also takes into consideration the factors that prevent the Basic Education teachers to invest in their studies.

Keywords: Continuing Education. Ethnic-Racial Relations. PENESB/UFF

\section{Introdução}

ano de 2018 é um ano particularmente rico de significados para a te-
mática racial no Brasil. Primeiramente pelo aniversário de 130 da Lei Áurea, mas também por completar 15 anos de aprovação de Lei 10.639 de 2003 que alterou a Lei de Diretrizes e Bases da Educação Nacional (LDBEN), Nº 9.394 de 1996 e inseriu, nos mais diferentes níveis educacionais brasileiros, a obrigatoriedade do ensino da História e Cultura Afro-Brasileira.

Todavia, em um cenário de crise institucional, social e política em que políticas de estado e órgãos promovedores de reconhecimento e reparação de dívidas sociais, são fechados, como por exemplo a SEPPIR (Secretaria Especial de Políticas de Promoção da Igualdade Racial) e o CNPIR (Conselho Nacional de Promoção da Igualdade Racial), nos indagamos se existemmotivos para festejarmos?

Então, considerando esse contexto político educacional e a partir da nossa experiência frente às ações formativas desenvolvidas pelo Programa de Estudo do Negro na Sociedade Brasileira (PENESB) da Universidade Federal Fluminense (UFF), fundado e coordenado pela professora Iolanda de Oliveira, em 1995, portanto oito anos antes da implantação da Lei 10639/03, já demonstrava, assim, uma preocupação com 
a Educação da população negra no Brasil. E uma das possíveis ações/soluções em prol de uma Promoção da Igualdade Racial no Brasil pelo viés educacional é o investimento na formação continua para as Relações Étnico-Raciais.

Após completar 15 anos de aprovação da Lei no 10.639/2003, percebemos que sua implantação ainda encontra inúmeros entraves, dentre as dificuldades de assimilação e execução no ambiente escolar destacamos como principais fatores:

- Ausênciade conhecimento teórico do professorado;

- a formação docente inicial insuficiente para abordar em sala de aula tais questões;

- enfrentamento com o fim da desconstrução do mito da democracia racial;

- isso tudo alicerça a concepção docente e os pilares que a educação brasileira foi constituída.

O sistema escolar tem características hierárquicas seletivas e é "racializado". Que vem sendo construído desde o século passado com o objetivo de integrar seletivamente a pobres e negros. Segundo Arroyo (2007, p. 116) "nosso sistema é das décadas de 1930-1950, quando se coloca o problema da integração dos setores populares, às massas urbanas. Décadas em que a ideologia da democracia racial estava no auge”. Como destaca Arroyo (2007), é no contexto ditado pela ideologia da democracia racial que o sistema escolar público promoverá uma "inclusão excludente" ou uma "integração seletiva" concluindo, portanto, que o sistema educacional vigente traz consigo um vício de origem que é muito eficaz para os propósitos excludentes pelo qual foi estruturado, isso perpassa pela formação docente e desagua no chão da sala de aula potencializandoa exclusão, pois desconstruir esta situação é mexer na estrutura racista da sociedade brasileira.

Segundo Munanga (2005, p. 63), 
A FORMAÇ̃̃O DOCENTE CONTINUADA PARA AS RELAÇÕES ÉTNICO-RACIAIS NO RIO DE JANEIRO: A EXPERIÊNCIA DO PROGRAMA DE ESTUDO SOBRE O NEGRO NA SOCIEDADE BRASILEIRA (PENESB/UFF)

[...] a formação de professores que não tiveram em sua base de formação a história da África, a cultura do negro no Brasil e a própria história do negro de um modo geral se constitui no problema crucial das novas leis que implementaram o ensino da disciplina nas escolas. E isso não simplesmente por causa da falta de conhecimento teórico, mas, principalmente, porque o estudo dessa temática implica no enfrentamento e derrubada do mito da democracia racial que paira sobre o imaginário da grande maioria dos professores.

A mudança nos métodos pedagógicos e uma formação docente que ofereçam subsídios para os professores trabalharem com a diversidade de forma igualitária, respeite e valorize as diferenças, são elementos imprescindíveis para estimular uma perspectiva cultural que abarque a complexidade das culturas e das experiências humanas, tanto a nível local quanto a nível global. Para avançarmos, precisamos compreender, de fato, a Lei 10.639/03, a Resolução CNE/CP 01/2004, Parecer CNE/CP 03/2004 e as Diretrizes Curriculares Nacionais para a Educação das Relações Étnico-Raciais e para o Ensino de História e Cultura Afro-Brasileira e Africana 10/2004 dentro do sistema complexo que são as Relações Étnico-Raciais no Brasil. Uma vez que, como observa Gomes (2011, p. 116):

A lei e as diretrizes entram em confronto com as práticas e com o imaginário racial presentes na estrutura e no funcionamento da educação brasileira, tais como o mito da democracia racial, o racismo ambíguo, a ideologia do branqueamento e a naturalização das desigualdades raciais.

Partindo dessas perspectivas e levando em conta quea formação continuada está prevista em documentos oficiais que se tornam marcadores legais no campo educacional, apresentaremos o compilado legislativo que tange a formação continuada do docente, desaguando mais adiante na especificidade da problemática relativa a Educação das Relações Étnico-Raciais e seus marcos legais. E, por fim, dissertaremos sobre as ações formativas desenvolvidas pelo PENESB/UFF através de curso de formação 
continuada me nível de especialização no campo da Educação e Relações Raciais para professores da Educação Básica, tendo como enfoque principal, analisar a concepção teórico-metodológica em que se baseia as referidas ações formativas, que as tornam originais e diferenciadas frente as demais ofertas de curso no estado do Rio de Janeiro.

\section{Formação continuada e os marcos legais: breves reflexões}

Falar de formação continuada nos faz subentender que houve uma formação inicial e que se pretende galgar novos passos. Pensamos que, antes de falarmos do presente é necessário visitar o passado para lembrar-se de onde saímos, e conjecturar para aonde estamos caminhando.

Em 20 de dezembro de 1996 foi promulgada a Lei no 9.394/96, com as Diretrizes e Bases da Educação Nacional (LDBEN), sendo esta, atualmente,um dos marcos legais de maior influência nas políticas públicas de formação continuada. O texto da LDBEN discorre por 9 capítulos sendo o capítulo VI (artigos 61 ao 67) destinado aos Profissionais da Educação, instituindo no artigo 62 critérios para o exercício docente na Educação Básica, estabelecendo no seu parágrafo $1^{\circ}$ que "A União, o Distrito Federal, os Estados e os Municípios, em regime de colaboração, deverão promover a formação inicial, a continuada e a capacitação dos profissionais de magistério". Acrescenta ainda no parágrafo $2^{\circ}$ que "A formação continuada e a capacitação dos profissionais de magistério poderão utilizar recursos e tecnologias de educação a distância.” (BRASIL, 1996).

Percebemos que no primeiro parágrafo $1^{\circ}$ o verbo “deverão" tem caráter obrigatório, ou seja, a formação continuada não é facultativa as esferas governamentais e sim tem um caráter de obrigatoriedade que deve ser assumido pelos gestores públicos 
A FORMAÇ̃̃O DOCENTE CONTINUADA PARA AS RELAÇÕES ÉTNICO-RACIAIS NO RIO DE JANEIRO: A EXPERIÊNCIA DO PROGRAMA DE ESTUDO SOBRE O NEGRO NA SOCIEDADE BRASILEIRA (PENESB/UFF)

como prioridade. Já no parágrafo $2^{\circ}$ o verbo “poderão”tem caráter permissivo, no sentido de que os recursos disponibilizados pelo Ministério da Educação e Cultura (MEC) não precisam ser direcionados para cursos de formação. Ou seja, o texto da lei não estabelece para os gestores quais valores devem ser aplicados na formação continuada dos docentes.

O Artigo 62A, em seu Parágrafo Único:

Garantir-se-á formação continuada para os profissionais a que se refere ocaput, no local de trabalho ou em instituições de educação básica e superior, incluindo cursos de educação profissional, cursos superiores de graduação plena ou tecnológicos e de pós-graduação (BRASIL, 1996).

O texto abre prerrogativa para possíveis formações em escalas macro e micro dentro dos sistemas de ensino. O que coaduna com o artigo 63, estabelecendo aos institutos superiores de educação como mantenedores de programas de educação continuada para os profissionais de educação nos diversos níveis, consoante ao inciso III.

Encerrando o capítulo VI com o artigo 67, a lei delibera que os sistemas de ensino promovam a valorização dos profissionais da educação através, também, do aperfeiçoamento profissional continuado, inclusive com licenciamento periódico remunerado para esse fim, conforme inciso II.

O MEC, buscando fortalecer a ações articuladas com os sistemas de ensino de combate a desigualdade social, institui em 2004 a Secretaria de Educação Continuada, Alfabetização e Diversidade (SECAD), atualmente, Secretaria de Educação Continuada, Alfabetização, Diversidade e Inclusão (SECADI), sendo esta a responsável por contribuir com a efetivação de políticas públicas para o "desenvolvimento inclusivo 
dos sistemas de ensino, voltado à valorização das diferenças e da diversidade, à promoção da educação inclusiva, dos direitos humanos e da sustentabilidade socioambiental".

Em 2004 o MEC amplia a ações da SECADI, através da Rede Nacional de Formação Continuada de Professores, buscando fomentar - em áreas de concentração como alfabetização e linguagem, educação matemática e científica, ensino de ciências humanas e sociais, artes e educação física - a melhoria na formação de professores da Educação Básica da rede pública de ensino, contribuindo assim para o processo de ensino e aprendizagem do corpo discente.

Imbernón (2010) faz críticas à estrutura existente em prol da formação continuada docente, afirmando que são necessárias mudanças tanto nas políticas públicas quanto na prática docente, pois os últimos anos tais ações assumiram caráter pontuais e descontinuadas. Embora este seja um processo dinâmico de constante reflexão, percebemos que a práxis docente dominante no cotidiano ainda se resume a ações uniformes e simplistas.

Outro marco representativo para a formação continuada do Professor é apontado pelo Plano Nacional de Educação (PNE) - Decênio 2014a 2024, que apresenta um conjunto de 10 diretrizes orientadoras para implantação de estratégias para execução de 20 metas, distribuídas em 4 blocos para avançar ao longo do decênio.

O primeiro bloco trata da garantia de acesso à matrícula; O segundo propõe a redução das desigualdades e à valorização da diversidade; O terceiro apresenta as metas que tratam da valorização dos profissionais da educação; o quarto, e último, se refere ao Ensino Superior.Nos deteremos no bloco três, especialmente meta 16, que explicita como objetivo: 
A FORMAÇ̃̃O DOCENTE CONTINUADA PARA AS RELAÇÕES ÉTNICO-RACIAIS NO RIO DE JANEIRO: A EXPERIÊNCIA DO PROGRAMA DE ESTUDO SOBRE O NEGRO NA SOCIEDADE BRASILEIRA (PENESB/UFF)

Formar, em nível de pós-graduação, cinquenta por cento dos professores da educação básica, até o último ano de vigência deste PNE, e garantir a todos (as) os (as) profissionais da educação básica formação continuada em sua área de atuação, considerando as necessidades, demandas e contextualizações dos sistemas de ensino.(BRASIL, 2014, p. 35).

Embora apenas a meta 16 seja específica enquanto a formação continuada há outras que são estratégicas e compreendem tal formaçãocomopilar para o alcance de outras demandas.

Tabela 1 - Outras metas e a questão formação docente continuada. Estratégias e ações adotadas para a implementação e a execução do PNE.

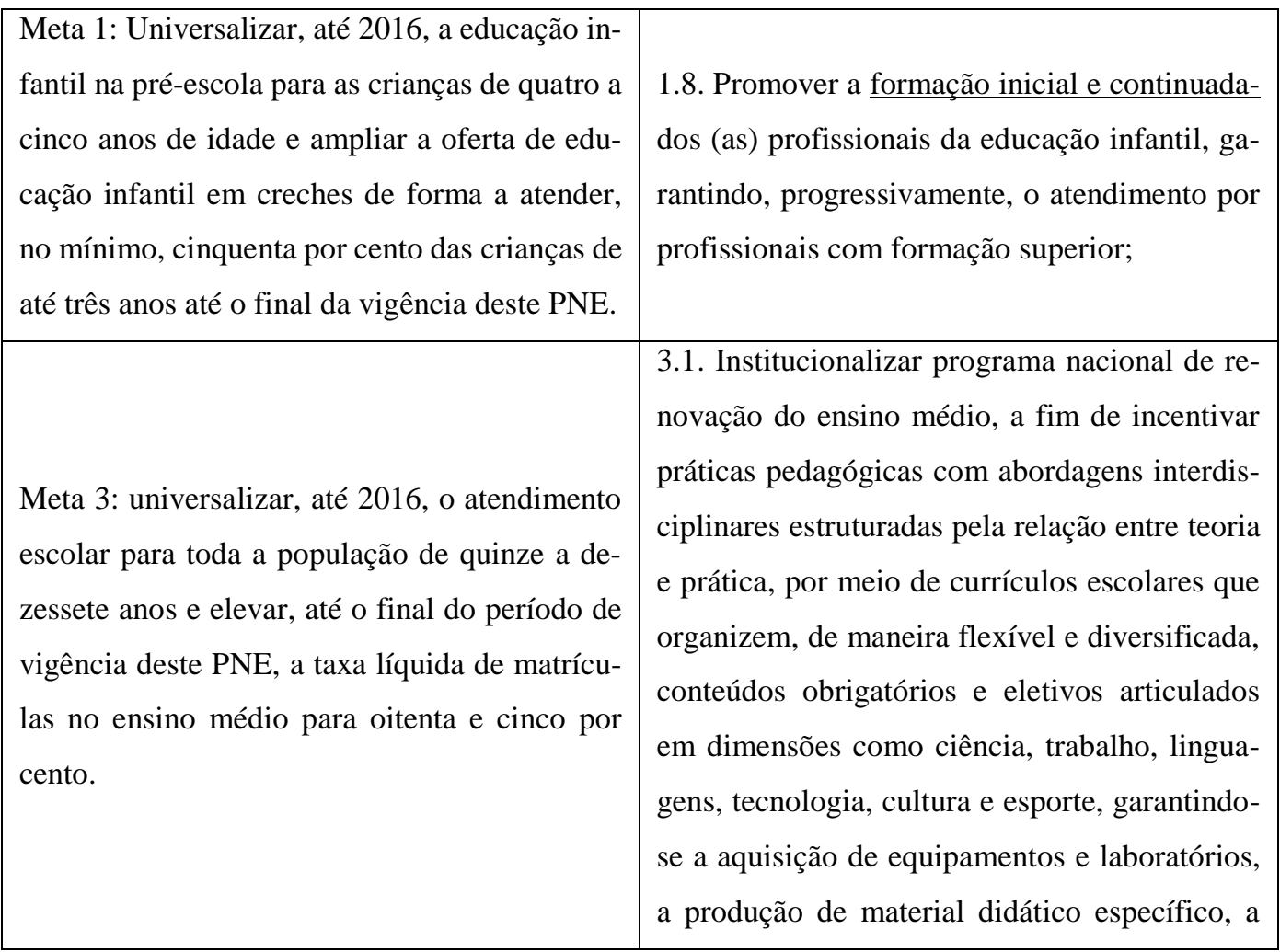

Cadernos de Pós-graduação, São Paulo, v. 17, n. 2, p. 75-97, jul./dez. 2018. 


\begin{tabular}{|c|c|}
\hline & $\begin{array}{l}\text { formação continuada de professorese a articula- } \\
\text { ção com instituições acadêmicas, esportivas e } \\
\text { culturais. }\end{array}$ \\
\hline $\begin{array}{l}\text { Meta 4: universalizar, para a população de qua- } \\
\text { tro a dezessete anos com deficiência, transtor- } \\
\text { nos globais do desenvolvimento e altas habili- } \\
\text { dades ou superdotação, o acesso à educação bá- } \\
\text { sica e ao atendimento educacional especiali- } \\
\text { zado, preferencialmente na rede regular de en- } \\
\text { sino, com a garantia de sistema educacional in- } \\
\text { clusivo, de salas de recursos multifuncionais, } \\
\text { classes, escolas ou serviços especializados, pú- } \\
\text { blicos ou conveniados. }\end{array}$ & $\begin{array}{l}\text { 4.3. Implantar, ao longo deste PNE, salas de re- } \\
\text { cursos multifuncionais e fomentar a formação } \\
\text { continuada de professores e professoras para o } \\
\text { atendimento educacional especializado nas es- } \\
\text { colas urbanas, do campo, indígenas e de comu- } \\
\text { nidades quilombolas. } \\
\text { 4.18. Promover parcerias com instituições co- } \\
\text { munitárias, confessionais ou filantrópicas sem } \\
\text { fins lucrativos, conveniadas com o poder pú- } \\
\text { blico, visando a ampliar a oferta de formação } \\
\text { continuada e a produção de material didático } \\
\text { acessível, assim como os serviços de acessibili- } \\
\text { dade necessários ao pleno acesso, participação } \\
\text { e aprendizagem dos estudantes com deficiên- } \\
\text { cia, transtornos globais do desenvolvimento e } \\
\text { altas habilidades ou superdotação matriculados } \\
\text { na rede pública de ensino. }\end{array}$ \\
\hline $\begin{array}{l}\text { Meta 5: alfabetizar todas as crianças, no má- } \\
\text { ximo, até o final do terceiro ano do ensino fun- } \\
\text { damental. }\end{array}$ & $\begin{array}{l}\text { 5.6. Promover e estimular a formação inicial e } \\
\text { continuada de professores (as) para a alfabeti- } \\
\text { zação de crianças, com o conhecimento de no- } \\
\text { vas tecnologias educacionais e práticas pedagó- } \\
\text { gicas inovadoras, estimulando a articulação en- } \\
\text { tre programas de pós-graduação stricto sensu e } \\
\text { ações de formação continuada de professores } \\
\text { (as) para a alfabetização. }\end{array}$ \\
\hline $\begin{array}{l}\text { Meta 7: fomentar a qualidade da educação bá- } \\
\text { sica em todas as etapas e modalidades, com me- } \\
\text { lhoria do fluxo escolar e da aprendizagem de }\end{array}$ & $\begin{array}{l}\text { 7.4. Induzir processo contínuo de autoavaliação } \\
\text { das escolas de educação básica, por meio da } \\
\text { constituição de instrumentos de avaliação que }\end{array}$ \\
\hline
\end{tabular}

Cadernos de Pós-graduação, São Paulo, v. 17, n. 2, p. 75-97, jul./dez. 2018. 
A FORMAÇ̃̃O DOCENTE CONTINUADA PARA AS RELAÇÕES ÉTNICO-RACIAIS NO RIO DE JANEIRO: A EXPERIÊNCIA DO PROGRAMA DE ESTUDO SOBRE O NEGRO NA SOCIEDADE BRASILEIRA (PENESB/UFF)

\begin{tabular}{|c|c|}
\hline $\begin{array}{l}\text { modo a atingir as seguintes médias nacionais } \\
\text { para o IDEB [...] }\end{array}$ & $\begin{array}{l}\text { orientem as dimensões a serem fortalecidas, } \\
\text { destacando-se a elaboração de planejamento es- } \\
\text { tratégico, a melhoria contínua da qualidade } \\
\text { educacional, a formação continuada dos (as) } \\
\text { profissionais da educaçãoe o aprimoramento da } \\
\text { gestão democrática; } \\
\text { 7.22. Informatizar integralmente a gestão das } \\
\text { escolas públicas e das secretarias de educação } \\
\text { dos estados, do Distrito Federal e dos municí- } \\
\text { pios, bem como manter programa nacional de } \\
\text { formação inicial e continuada para o pessoal } \\
\text { técnico das secretarias de educação; } \\
\text { 7.26. consolidar a educação escolar no campo } \\
\text { de populações tradicionais, de populações itine- } \\
\text { rantes e de comunidades indígenas e quilombo- } \\
\text { las, respeitando a articulação entre os ambientes } \\
\text { escolares e comunitários e garantindo: o desen- } \\
\text { volvimento sustentável e preservação da identi- } \\
\text { dade cultural; a participação da comunidade na } \\
\text { definição do modelo de organização pedagó- } \\
\text { gica e de gestão das instituições, consideradas } \\
\text { as práticas socioculturais e as formas particula- } \\
\text { res de organização do tempo; a oferta bilíngue } \\
\text { na educação infantil e nos anos iniciais do en- } \\
\text { sino fundamental, em língua materna das comu- } \\
\text { nidades indígenas e em língua portuguesa; a re- } \\
\text { estruturação e a aquisição de equipamentos; a } \\
\text { oferta de programa para a formação inicial e } \\
\text { continuada de profissionais da educação; e o }\end{array}$ \\
\hline
\end{tabular}

Cadernos de Pós-graduação, São Paulo, v. 17, n. 2, p. 75-97, jul./dez. 2018. 


\begin{tabular}{|c|c|}
\hline $\begin{array}{l}\text { Meta 10: oferecer, no mínimo, vinte e cinco por } \\
\text { cento das matrículas de educação de jovens e } \\
\text { adultos, nos ensinos fundamental e médio, na } \\
\text { forma integrada à educação profissional. }\end{array}$ & $\begin{array}{l}\text { 10.7. Fomentar a produção de material didático, } \\
\text { o desenvolvimento de currículos e metodolo- } \\
\text { gias específicas, os instrumentos de avaliação, } \\
\text { o acesso a equipamentos e laboratórios e a for- } \\
\text { mação continuada de docentes das redes públi- } \\
\text { cas que atuam na educação de jovens e adultos } \\
\text { articulada à educação profissional. }\end{array}$ \\
\hline $\begin{array}{l}\text { Meta 15: garantir, em regime de colaboração } \\
\text { entre a União, os estados, o Distrito Federal e } \\
\text { os municípios, no prazo de um ano de vigência } \\
\text { deste PNE, política nacional de formação dos } \\
\text { profissionais da educação de que tratam os in- } \\
\text { cisos I, II e III do caput do art. } 61 \text { da Lei no } \\
\text { 9.394, de } 20 \text { de dezembro de } 1996 \text {, assegurado } \\
\text { que todos os professores e as professoras da } \\
\text { educação básica possuam formação específica } \\
\text { de nível superior, obtida em curso de licencia- } \\
\text { tura na área de conhecimento em que atuam. }\end{array}$ & $\begin{array}{l}\text { 15.4. Consolidar e ampliar plataforma eletrô- } \\
\text { nica para organizar a oferta e as matrículas em } \\
\text { cursos de formação inicial e continuada de pro- } \\
\text { fissionais da educação, bem como para divulgar } \\
\text { e atualizar seus currículos eletrônicos; }\end{array}$ \\
\hline
\end{tabular}

Fonte: Elaborada a partir das Metas e Estratégias do PNE 2014 a 2024 (BRASIL, 2014). (Grifo nosso).

Dada a relevância da formação continuada, é reconhecido através do Plano Nacional de Educação que para atingir objetivos propostos é necessário investir no grupo de profissionais de educação.

Portanto, estabelecer política de valorização dos profissionais da educação em cada rede ou sistema de ensino é fundamental para que a política educacional se fortaleça. Quanto mais sustentáveis forem as carreiras e quanto mais integradas forem as decisões relativas à formação mais ampliadas serão as perspectivas da equidade da oferta educacional. (BRASIL, 2014, p.13). 
A FORMAÇÃO DOCENTE CONTINUADA PARA AS RELAÇÕES ÉTNICO-RACIAIS NO RIO DE JANEIRO: A EXPERIÊNCIA DO PROGRAMA DE ESTUDO SOBRE O NEGRO NA SOCIEDADE BRASILEIRA (PENESB/UFF)

A formação continuada docente para as relações étnico-raciais: discussões iniciais

A análise dos dados do Censo escolar referente ao ano de 2014 demonstrou uma que mesmo mais da metade da população brasileira (50,7\%) declarou-se negra, tal população não está representada na mesma proporção nos níveis elevados educacionais. Ou seja, quanto maior o tempo de escolarização, menor é o percentual de negros nas salas de aula. Enquanto na educação infantil o acesso da população branca é de 42,9\%, os negros são 39,8\%. Os números melhoram consideravelmente durante o ensino fundamental, praticamente não existindo diferenças entre negros e brancos (ambas atingem 92\%). Todavia, durante o ensino médio a queda da frequência líquida de negros e brancos volta a apresentar a profunda desigualdade racial do nosso país, enquanto a permanência de negros é de pouco mais de 49\%, os brancos são de 63,7\% (BRASIL, 2015).

Os dados apresentados traduzem em números a realidade brasileira baseada na desigualdade racial, especialmente na educação e corroboram para a necessidade do enfrentamento comprometido por parte de gestores públicos nos mais diferentes níveis tendo em vista oferecer respostas para a problemática.Nesse sentido o Parecer 03/2004 ressalta a importância das políticas de reparação, explicando que reconhecer tal demanda "exige que os estabelecimentos de ensino, frequentados em sua maioria por população negra"(BRASIL, 2013, p. 499), tenham professores compromissados na educação para as relações étnico-raciais.

Imbernón (2010) ressalta que a análise do contexto político-social é elemento imprescindível na formação, ou seja, as demandas postas precisam ser refletidas e poli- 
tizadas pelos sujeitos envolvidos. Nesta mesma perspectiva, em 2004, através de reivindicações e propostas do Movimento Negro, apontadas ao longo do século XX, foi registrada a necessidade de políticas públicas que promovessem a valorização da história e cultura dos afro-brasileiros e africanos nas escolas através de diretrizes, conforme apontado pelo Parecer 003/2004. (BRASIL, 2013).

Buscando a ruptura com o fundamentalismo pedagógico² ${ }^{2}$ arcado pelo etnocentrismo europeu, alicerçado na reprodução do que está posto, este tem caráter inibidor ao ato de questionar, sendo este último compreendido como ameaças ao convívio social (LIMA, 2009) entendemos que a formação continuada de professores para a educação das relações étnico-raciais é uma ferramenta para romper com o status quo.

Segundo Silvio Gallo (2009) essas características que emanam do fundamentalismo pedagógico são facilmente identificados em políticas públicas educacionais, nos Projetos Político-Pedagógicos (PPP) das unidades escolares e nas práticas docente.

$\mathrm{Na}$ tentativa de descontinuar com ações aplicadas nas instituições escolares desde outrora, o Parecer $03 / 2004^{3}$ menciona que para o tipo de política que se pretende implementar sãonecessáriosprofessores“com formação [adequada] para lidar com as tensas relações produzidas pelo racismo e discriminações” (BRASIL, 2013, p. 498).

A formação continuada mostra-se como ação imprescindível para tema proposto através da alteração da LDBEN n 9.394/96 nos artigos 26A e 79B instituído pela Lei 10.639/03, evitando a improvisação, conforme o Parecer 03/2004 aponta:

Para obter êxito, a escola e seus professores não podem improvisar. Têm que desfazer mentalidade racista e discriminadora secular, superando o etnocentrismo europeu, reestruturando relações étnicoraciais e sociais, desalienando processos pedagógicos. (BRASIL, 2013, p. 501).

Cadernos de Pós-graduação, São Paulo, v. 17, n. 2, p. 75-97, jul./dez. 2018. 
A FORMAÇ̃̃O DOCENTE CONTINUADA PARA AS RELAÇÕES ÉTNICO-RACIAIS NO RIO DE JANEIRO: A EXPERIÊNCIA DO PROGRAMA DE ESTUDO SOBRE O NEGRO NA SOCIEDADE BRASILEIRA (PENESB/UFF)

Para discutir sobre o improviso na Educação para as Relações Étnico-raciais é importante trazer as perspectivas de Oliveira (2006). Ao se debruçado sobre as questões do cenário político, do planejamento escolar, e das práticas pedagógicas, a autora cita que o período político é fator preponderante para corrente pedagógica aplicada na escola, pois este definirá os princípios e fins da educação no país.Para ela um dos possíveis caminhos é o uso da pedagogia progressista, por tratar-se deuma "concepçãopedagógica que contém os elementos necessários a uma atuaçãocomprometida com a transformação da sociedade e, portanto, com a eliminação de qualquer tipo de discriminação"(OLIVEIRA, 2006, p.50), e que, portanto, auxilia na orientação da formação de profissionais da educação em prol da diversidade racial brasileira.

Estamos em consonância com Oliveira por entendermos que essa transformação socialinicia-se no planejamento escolar, evitando improvisos. Ou seja, "A ênfase no planejamento é dada no sentido de que se tenha a possibilidade de promover as mudanças que se fazem necessáriaspara garantir a igualdade racial em educação". (OLIVEIRA, 2006, p. 46). Cabendo aos professores autonomia e preparo para atuarem politicamente sobre os conteúdos escolares em prol de uma educação antirracista. Neste sentido, o planejamento antecede a ação docente, onde vai predizer os objetivos, as habilidades e as competências, que deverão considerar a população negra na perspectiva de valorização e reconhecimento da história, identidade e cultura dos afro-brasileiros e dos africanos, conforme apontamas Diretrizes Curriculares Nacionais da Educação das Relações Étnico-Raciais (BRASIL, 2004).

Bento (2002) aponta que tais iniciativas são apresentadas como esforços para combater o soterramento da história e cultura afro-brasileira e africana, confrontando práticas docentes que silenciam, mutilam e distorcem a temática racial, investindo no 
imaginário coletivo sobre os negros de forma depreciativa, pejorativas e os desumanizados. Assim, a desvalorização sobre o negro apresentada nos documentos norteadores produzidos pelas escolas na perspectiva do fundamentalismo pedagógico, provoca no aluno o não sentimento de pertença a esse grupo étnico-racial, “descontente e desconfortável com sua condição de negro, procura identificar-se como branco.” (Idem, p. 1).

Bento questiona o ditame da branquitude, que para ela, trata-se de processo histórico em que o branqueamento da população foi realizado através da imigração europeia, e a implantação de ações simbólicas e concretas para o reforço do racismo. Deste modo, "Eles reconhecem as desigualdades raciais, só que não associam essas desigualdades raciais à discriminação e isto é um dos primeiros sintomas da branquitude" (BENTO, 2002, p.2). É uma desigualdade reconhecida, porém não associada à estratégia alternativa para manter o estado de equilíbrio da elite dominante.

Compreendemos que tal situação passa pelo chão da sala de aula, desta maneira uma das ações de transformação começa pela formação dos educadores para a igualdade racial. No processo de formação que respeite a legislação, e que de forma dinâmica auxilie nas ações concretas do engajamento político e social. Onde tais leis, decretos e pareceres, fruto das intensas lutas dos movimentos negros, passam a adquirir concretude da vida vivida e, sirvam de fato para a transformaçãopolítico-social, visando relações étnico-raciais igualitárias.

\section{A experiência dos cursos de especialização do PENESB/UFF}

Em 1995, foi aprovada pela Reitoria da Universidade Federal Fluminense (UFF) a implementação do Programa de Educação sobre o Negro na Sociedade Brasileira (PENESB), na Faculdade de Educação. ${ }^{4}$ Uma iniciativa pioneira, que antecedeu em sete anos a criação da própria lei 10.639/2003, sinal do olhar atento de professores 
A FORMAÇÃO DOCENTE CONTINUADA PARA AS RELAÇÕES ÉTNICO-RACIAIS NO RIO DE JANEIRO: A EXPERIÊNCIA DO PROGRAMA DE ESTUDO SOBRE O NEGRO NA SOCIEDADE BRASILEIRA (PENESB/UFF)

e pesquisadores comprometidos com ações pedagógicas de transformação da realidade em prol de uma educação antirracista. Objetivando

realizar pesquisas sobre a dimensão racial do fenômeno educativo de modo paralelo à disseminação dos conhecimentos sobre o tema, junto à população em geral e em especial junto aos profissionais da educação, interferindo na sua formação inicial e continuada. (PENESB, 1996-1997apud SANTOS, 2007, p. 67).

Tal aspiração, de levar as reflexões extramuros da universidade, se concretiza em iniciativas como, por exemplo, a organização e promoção de eventos em que os participantes estavam vinculados à UFF, mas também à população em geral. Deste modo, a equipe PENESB possibilitava

aos profissionais da Educação e à população em geral a oportunidade de ter acesso à produção de saberes e às práticas pedagógicas que visam explicar e interferir na dimensão racial do fenômeno educativo, com o propósito de reduzir os altos índices de seletividade escolar determinados pelo fator racial. (SANTOS, 2007, p. 68).

O compromisso firmado pelo PENESB, na promoção de uma educação igualitária racialmente, se concretizou - entre os anos de 1995 e 2007 - na oferta de cinco turmas de curso, com média de 35 alunos cada (cerca de 175 concluintes), em nível de especialização, que abordavam a temática das relações étnico-raciais.

A partir de 2009 há uma grande reformulação na atuação do curso PENESB, os cursos passam a ser ministrado à distância. "A experiência exitosa do PENESB com o primeiro grupo de formação continuada a distância, em nível de extensão, motivou o Programa a ousar a oferta do mesmo curso em nível de especialização na mesma modalidade" (OLIVEIRA, 2016, p.8). 
Entretanto, uma preocupação da equipe PENESB consistia em manter a qualidade e excelência que fez do curso um espaço reconhecido, e da sua produção uma referência. A solução encontrada foi o uso de uma modalidade "semipresencial". Em que os alunos poderiam ter acesso aos textos e a inúmeros recursos audiovisuais (como vídeos, músicas e etc.) referente a cada disciplina, e enviar, por meio da plataforma moodle, as tarefas de acordo com o cronograma planejado pela coordenação. O diferencial estava na "aula presencial" que dava início a cada componente curricular.

A proposta do PENESB orientou-se pelo princípio de que a questão principal dos cursos, tanto os de formação inicial, quanto continuada, está vinculada à garantia de qualidade, independente da qualidade da modalidade de ensino em que são oferecidos. Entende-se que em ambas as modalidades, presencial e a distância, respeitandose as particularidades de cada uma, há de se considerar a necessidade de estabelecer critérios de qualidade e uma organização e dinâmica que impeçam o aligeiramento e superficialidade da formação oferecida, isto é, que garantam um nível de ensino compatível com uma atuação docente devidamente qualificada (OLIVEIRA, 2016, p.8).

Disciplinas como "História da África", "O Negro na História do Brasil” e "Teoria Social e Relações Raciais” contaramcom grandes especialistas reconhecidos no campo. Dentre eles, respectivamente, podemos citar os professores Mônica Lima (UFRJ), Marta Abreu (UFF) e Kabengele Munanga (USP). O que demonstra o compromisso com qualidade teórica e o esforço, por parte da equipe PENESB na manutenção de vínculos com pesquisadores comprometidos em "uma formação dos profissionais da educação que dê conta da eliminação deste problema que atinge toda a humanidade" (OLIVEIRA, 2006, p. 128).

Além disso, tal atenção à qualidade se demonstrou através da seleção do corpo de tutores com pesquisas na pós-graduação stricto senso, voltadas para a temática das 
A FORMAÇÃO DOCENTE CONTINUADA PARA AS RELAÇÕES ÉTNICO-RACIAIS NO RIO DE JANEIRO: A EXPERIÊNCIA DO PROGRAMA DE ESTUDO SOBRE O NEGRO NA SOCIEDADE BRASILEIRA (PENESB/UFF)

relações raciais. Desta maneira, ocorre um acompanhamento apurado teórico e metodologicamente, sem perder de vistas a aplicabilidade prática em sala de aula e nos demais espaços de atuação dentro da sociedade.

Ressaltamos que, garantida a qualidade do curso, a modalidade a distância possui vantagens com relação a modalidade presencial, uma vez que, levando em conta o território complexo dos grandes centros urbanos como a Região Metropolitana do Rio de Janeiro, que implica em um considerável gasto financeiro e temporal no que tange no deslocamento, tal situação é amenizada, além de que a evasão também é muito menor, pois os professores da Educação Básica possuem pouco tempo para desenvolver outras atividades apara além o exercício da docência, uma vez que possuem jornadas duplas ou triplas para garantir salários razoáveis para a manutenção mínima da vida.

[...] os cursos de formação continuada a distância nos grandes centros urbanostêm vantagens sobre os cursos presenciais em relação a dois aspectos: redução significativa dos percentuais de desistência e maior assimilação dos conhecimentos curriculares por motivo da realização de tarefas semanais que exigem a leitura de textos básicos apresentados. Sugere-se que esta modalidade deva restringir-se aos grandes centros urbanos, como o Rio de Janeiro, cujos deslocamento, além do alto custo, exigem longo tempo para fazê-lo. Nos cursos presenciais, em geral, noturnos, os profissionais do magistério, tendo uma jornada de trabalho, não raro, dupla e em alguns casos tripla, em sua grande maioria, enfrentam intenso trânsito no deslocamento para universidade, além do aumento do custo deste deslocamento e dos gastos com alimentação fora do espaço residencial, o que provavelmente leva desistência de elevados percentuais dos que se propõem a frequentar os cursos. Além desses fatores, a falta de apoio institucional para continuidade da formação também tem, possivelmente, implicações nos percentuais de desistência, fator este que independe da modalidade. (OLIVEIRA, 2016, p.8).

Vale informar que apesar do êxito e das inúmeras vantagens da modalidade a distância, o PENESB não recomenda a sua expansão sem critérios rigorosos com o fim 
de garantir a qualidade da formação ofertada. A luta sempre deve ser pela oferta da formação inicial e continuada presenciais, "porque entendemos que a educação institucionalizada, embora priorize o conhecimento acadêmico, se dá no âmbito das relações humanas, nas quais o fator emocional, a afetividade, não pode estar ausente" (OLVEIRA, 2016, p. 8).

Nossa preocupação no campo afetivo se dá, por conta que as discussões sobre as Relações Étnico-Raciais sempre impactam no afloramento de sentimentos não trabalhados, escondidos e, muitas vezes revelados de forma violenta e traumatizantes. Como destacou Ana Maria Gonçalves (MELO, s/d) o "racismo é algo que afeta tanto quem o manifesta quanto quem é alvo dele, independente da relação entre estas pessoas, interferindo na quantidade e na qualidade dos sentimentos e das emoções." E Oliveira (2016) ratifica tal posição ao afirmar que:

Tratando-se da educação para as relações raciais, cujos conhecimentos afetam fortemente as emoções de negros e brancos, não se restringindo ao âmbito intelectual, na educação a distância, a afetividade não desaparece totalmente, mas é reduzida pela mediação tecnológica. O contato mediado pela tecnologia impede que o professor online estimule o cursista através de outras linguagens além da escrita, principalmente por meio das expressões e relações corporais diretas (OLIVEIRA, 2016, p. 9).

Assim, o curso em nível de especialização em Educação e Relações ÉtnicoRaciais do oferecido pelo PENESB, tem como os seguintes objetivos:

1. Oferecer aos profissionais em exercício na Escola Básica, oportunidade de:

$\checkmark$ Adquirir conhecimentos que lhes possibilitem compreender e interferir na situação da população negra no sistema nacional da educação, por meio da revisão da sua prática pedagógica, com vistas a uma pedagogia que promova a real democratização das oportunidades educacionais; 
A FORMAÇ̃̃O DOCENTE CONTINUADA PARA AS RELAÇÕES ÉTNICO-RACIAIS NO RIO DE JANEIRO: A EXPERIÊNCIA DO PROGRAMA DE ESTUDO SOBRE O NEGRO NA SOCIEDADE BRASILEIRA (PENESB/UFF)

$\checkmark$ Desenvolver a habilidade de incluir os referidos conhecimentos no seu planejamento pedagógico e, consequentemente, garantir o domínio desses conhecimentos pelos alunos, a fim de tornar as relações raciais entre os estudantes respeitosas e dialógicas, com vistas à incorporação de tais comportamentos nas relações raciais em todos os espaços sociais.

2. Despertar nos cursistas a confiança no potencial dos estudantes pretos e pardos, com o propósito de tornar as relações professoraluno negro capazes de promover a equidade racial;

3. Contribuir para alterar o quadro de desigualdades raciais na educação brasileira (OLIVEIRA, 2016, p.9)

Os referenciais teórico-metodológicos utilizados pelo PENESB foram descritos por Oliveira (2006) como tendo como objetivo primaz inserir a educação a serviço da sociedade brasileira, tendo como ponto central as questões relacionadas à população negra. São eles:

4. Formação fundamentada em uma concepção pedagógica comprometida com a promoção do negro;

5. Estabelecimento da relação de unidade entre teoria e prática;

6. A questão dos valores em educação;

7. A pesquisa ação como metodologia de investigação da própria prática e ou da prática do outro;

8. A legislação brasileira pertinente à educação da população negra e afins (OLIVEIRA, 2006, p.129).

Notamos que tais referenciais visam dinamizar o trabalho docente, inserindo intencionalmente, ou seja é uma atuação política por parte do professorado, os conteúdos, de forma ativa, de modo a promover valores históricos e culturais afro-brasileiros e africanos. Deste modo a educação transforma-se em um instrumento de mudança da realidade concreta, considerando acima de tudo a cultura escolar que estava submetida à cultura do branqueamento. Cabe ao professor, portanto, recontextualizar conteúdos escolares tidos como "tradicionais" de modo a evidenciar traços fundamentais das inúmeras contribuições das populações negras no Brasil. 
Sendo assim, para Oliveira (2006) não há ação docente desvinculada da pesquisa, ao professor cabe um constante exercício de "planejamento e replanejamento" da sua prática pedagógica, buscando alinhá-la aos princípios da educação antirracista. Tal esforço ajudará aos alunos reconhecer criticamente sua condição na sociedade, intervindo e reordenando seu projeto de vida.

\section{Referência}

ARROYO, M. G.. A pedagogia multirracial popular e o sistema escolar. In: GOMES, Nilma Lino (Org.). Um olhar além das fronteiras: educação e relações raciais. Belo Horizonte: Autêntica, 2007. p. 111-130.

BRASIL. Presidência da República. Lei n 10.639, de 9.01.2003. Estabelece as diretrizes e bases da educação nacional, para incluir no currículo oficial da Rede de Ensino a obrigatoriedade da temática "História e Cultura Afro-Brasileira", e dá outras providências. Disponível em <http://www.planalto.gov.br/ccivil_03/leis/2003/L10.639.htm>. Acesso em: 18 out. 2018.

Diretrizes Curriculares Nacionais para a Educação para as Relações ÉtnicoRaciais e para o Ensino de História e Cultura Afro-Brasileira e Africana. In: Diretrizes Curriculares Nacionais Gerais da Educação Básica. Ministério da Educação.Secretaria de Educação Básica. Diretoria de Currículos e Educação Integral. Brasília: MEC, SEB, DICEI, 2004. Disponível em: <http://www.acaoeducativa.org.br/fdh/wp-content/uploads/2012/10/DCN-s-Educacao-das-Relacoes-Etnico-Raciais.pdf $>$. Acesso em: 18 out. 2018.

Lei no. 9.394, de 20.12.1996. Estabelece as Diretrizes e Bases da Educação Nacional. Disponível em < http://www2.camara.leg.br/legin/fed/lei/1996/lei-9394-20-dezembro-1996-362578-publicacaooriginal-1-pl.html>. Acesso em: 18 out. 2018.

Plano Nacional de Educação 2014-2024 [recurso eletrônico]: Lei n 13.005, de 25 de junho de 2014, que aprova o Plano Nacional de Educação (PNE) e dá outras providências. Brasília: Câmara dos Deputados, Edições Câmara, 2014. Disponível em <http://www.observatoriodopne.org.br/uploads/reference/file/439/documento-referencia.pdf $>$. Acesso em: 21 jul. 17. 
A FORMAÇ̃̃O DOCENTE CONTINUADA PARA AS RELAÇÕES ÉTNICO-RACIAIS NO RIO DE JANEIRO: A EXPERIÊNCIA DO PROGRAMA DE ESTUDO SOBRE O NEGRO NA SOCIEDADE BRASILEIRA (PENESB/UFF)

. Ministério da Educação. Educacenso: O item cor/ raça no censo escolar da educação básica. 2015. Disponível em <http://download.inep.gov.br/educacao_basica/educacenso/documentos/2015/cor_raca.pdf>. Acesso em 20 out. 2017.

BENTO, Maria Aparecida da Silva. Branqueamento e branquitude no Brasil. In:__ Iray Carone. (Org.) Psicologia social do racismo - estudos sobre branquitude e branqueamento no Brasil. Petrópolis, RJ: Vozes, 2002. p. 25-58.

GALLO, Silvio. A Vila: microfacismo, fundamentalismo e educação. In:

NETO, José da Veiga Neto. (Org.) Fundamentalismo e Educação. Belo Horizonte: Autêntica. 2009. p. 17-35.

GOMES, Nilma Lino. Educação de Jovens e Adultos e questão racial: algumas reflexões iniciais. In: ; SOARES, Leôncio; GIOVANETTI, Maria Amélia. (Org.). Diálogos na Educação de Jovens e Adultos. Belo Horizonte: Autêntica, 2011. p. 109-121.

MELO, Joyce. Entrevista com Ana Maria Gonçalves. Correio Nagô. (S/D). Disponível em: <http://correionago.com.br/portal/relacao-entre-racismo-e-afetividade-e-temade-curso-a-ser-ministrado-por-ana-maria-goncalves/>. Acesso em 20 jan. 2018.

IMBERNÓN, Francisco. Formação continuada de professores. Porto Alegre: Artmed 2010.

LIMA, Walter Matias. Uma pequena apresentação. In: NETO, José da Veiga Neto. (Org.) Fundamentalismo e Educação. Belo Horizonte: Autêntica. 2009. p. 13-16.

MUNANGA, K. (Org.). Superando o racismo na escola. Brasília: Ministério da Educação, 2005.

OLIVEIRA, Iolanda. Raça, currículo e práxis pedagógicas. População negra e a educação escolar. Cadernos PENESB. n.7. Niterói: Quartet/EdUFF, 2006. p. 41-67.

; Educação para as relações raciais: Composição curricular, orientação didática e dinâmica de um curso de formação continuada para docentes da educação básica. In: PESSANHA, Marcia Maria de Jesus. (Org.). Educação e Relações Raciais. Curso Educação e Relações Étnico-Raciais. Volume 1. Niterói: CAED/UFF, 2016. p. 7-20.

SANTOS, Renato Emerson dos. O ensino de Geografia do Brasil e as relações raciais: reflexões a partir da lei 10.639. In: (Org.). Diversidade, espaço e relações étnicoraciais. O negro na Geografia do Brasil. Belo Horizonte: Autêntica, 2007. p. 21-42.

Cadernos de Pós-graduação, São Paulo, v. 17, n. 2, p. 75-97, jul./dez. 2018. 


\section{Notas:}

${ }^{1}$ Disponível em <http://portal.mec.gov.br/secretaria-de-educacao-continuada-alfabetizacaodiversidade-e-inclusao/apresentacao>. Acesso em 28/07/17.

${ }^{2}$ Fundamentalismo pedagógico é compreendido como um conjunto de princípios e valores para construção do currículo metodologias. Para melhor compreensão do conceito sugere-se a leitura: (GALLO, 2009).

3“'A Resolução 1/2004 institui as DCNERER que é aprovada pelo Parecer n 3/2004, da relatora Petronilha Beatriz Gonçalves e Silva

${ }^{4}$ Resolução número 121/1995 do Conselho de Ensino e Pesquisa do Centro de Estudos Aplicados da Faculdade de Educação da Universidade Federal Fluminense

recebido em 9 mar. 2018 / aprovado em 24 jul. 2018

\section{Para referenciar este texto:}

SOUZA, V. L.; SILVA, T. D.; MATTOS, T. P. A formação docente continuada para as relações étnico-raciais no Rio de Janeiro: a experiência do programa de estudo sobre o negro na sociedade brasileira (PENESB/UFF). Cadernos de Pós-graduação, São Paulo, v. 17, n.2, p. 7597, jul./dez. 2018. Disponível em: < https://doi.org/10.5585/cpg.v17n2.8456>. 